\title{
PENYAKIT FAMILIAL ASYMMETRICAL DOWLING DEGOS DENGAN TERAPI KOMBINASI LASER DAN BEDAH KIMIAWI SUPERFISIAL
}

\author{
Herjuni Oematan, Nyoman Suryawati, IGAA Praharsini, Herman Saputra* \\ Departemen Ilmu Kesehatan Kulit dan Kelamin \\ *Departemen Patologi Anatomi \\ FK Universitas Udayana/RSUP Sanglah Denpasar
}

\begin{abstract}
ABSTRAK
Dowling-Degos disease (DDD) merupakan penyakit genodermatosis jinak yang jarang terjadi, ditandai oleh pigmentasi berupa makula berwarna hitam kecoklatan dengan pola retikuler. Pengobatan penyakit ini biasanya sulit dan sering mengecewakan.

Seorang laki-laki, 18 tahun dengan keluhan timbul bercak hitam kecoklatan di bagian fleksural lengan kanan atas dan punggung yang terletak pada sisi kanan tubuh dengan awitan penyakit saat dewasa muda dan didapatkan riwayat keluarga dengan keluhan yang sama. Secara klinis pada bagian fleksural lengan kanan atas dan ketiak kanan didapatkan makula hiperpigmentasi multipel, batas tegas, bentuk bulat, yang konfluen membentuk bercak geografis, dan di sekitarnya tampak papul hiperpigmentasi membentuk pola retikuler. Pada sisi kanan punggung didapatkan papul hiperkeratotik folikuler comedo-like. Hasil pemeriksaan histopatologis mendukung diagnosis familial asymmetrical Dowling Degos disease. Pasien diterapi dengan formula Kligman, laser Q-Switched Nd:YAG $1064 \mathrm{~nm}$, dan peeling kimiawi superfisial. Prognosis kasus ini adalah dubia karena meskipun ukuran lesi berkurang namun lesi baru tetap muncul secara bertahap.
\end{abstract}

Kata kunci: Dowling-Degos disease, laser, peeling kimiawi

\section{FAMILIAL ASYMETRICAL DOWLING DEGOS DISEASE TREATED WITH COMBINATION OF LASER AND SUPERFICIAL CHEMICAL PEELING THERAPY}

\section{Korespondensi:}

Jl. Diponegoro, Bali, Denpasar Telp. 0361-257517

email: yunioematan@gmail.com

\begin{abstract}
Dowling-degos disease (DDD) is a rare benign genodermatosis disease, characterized by pigmentation as brownish black macules with reticulated pattern. Treatment of this disease usually difficult and often disappointing.

An 18-year-old man came with complaint of brownish-black patches on the flexural of his right arms and on the right side of his back. There is a positive family history for the same symptoms and the symptoms begin to appear on young adult period. Physical examination on the flexural of right arms and right axilla showed multiple hyperpigmented macules with well-defined margin and round shapes, some confluenced into geographical patches, surrounded by hyperpigmented papules forming reticulated pattern. On the right side of the back, there were comedo-like follicular hyperkeratotic papules. Result of histopathology examination support the diagnosis of familial asymmetrical Dowling Degos disease. Patient was treated with Kligman's formula topically, Q-Switched Nd:YAG laser of $1064 \mathrm{~nm}$, and superficial chemical peeling. The prognosis is uncertain, because even though the lesion diminished, new lesion can still continue to appear gradually.
\end{abstract}

Keyword: Dowling-Degos disease, laser, chemical peeling 


\section{PENDAHULUAN}

Dowling-Degos disease (DDD) atau dark dot disease adalah kelainan pigmen autosomal dominan yang jarang terjadi, disebabkan oleh defek gen yang terletak pada keratin. ${ }^{1}$ Dowling-Degos disease banyak dilaporkan di negara Asia dan Mediterania. ${ }^{2}$ Kejadian DDD yang dilaporkan di seluruh dunia tidak berbeda antara ras maupun jenis kelamin. ${ }^{3}$ Manifestasi klinis DDD didominasi pigmentasi dengan pola retikuler pada daerah fleksor, disertai comedo-like lesions dan pitted scars pada daerah perioral. ${ }^{4}$ Berdasarkan buku register poliklinik Kulit dan Kelamin Rumah Sakit Umum Pusat (RSUP) Sanglah Denpasar dalam waktu 5 tahun terakhir (20092015) belum pernah ditemukan kasus DDD. ${ }^{5}$

Pengobatan DDD biasanya sulit dan sering mengecewakan. ${ }^{6}$ Pemberian kortikosteroid topikal, agen depigmentasi, adapalen, memberikan hasil yang baik namun hanya bersifat sementara. ${ }^{2,6}$ Lesi berpigmen dapat diterapi dengan laser Quality-Switched Neodymium: Yttrium-Aluminium-Garnet (Q-Switched Nd:YAG) 1064 nm karena laser tersebut dapat berpenetrasi hingga ke lapisan dermis. ${ }^{7}$ Penelitian lebih lanjut berupa evaluasi klinis yang lebih panjang dan pengertian tentang imunopatogenesis dibutuhkan untuk mengevaluasi efikasi dan keamanan pilihan terapi yang bervariasi. ${ }^{6}$

Kasus ini dilaporkan karena familial DDD yang asimetris jarang dilaporkan sehingga dengan adanya laporan kasus ini dapat menambah pengetahuan untuk mengenal lesi DDD, gambaran histopatologis, dermoskopis serta menambah informasi bagi kalangan medis dalam memilih modalitas terapi yang tepat.

\section{KASUS}

Seorang pasien laki-laki, usia 18 tahun, suku Bali, warga negara Indonesia, status belum menikah, dirujuk oleh dokter spesialis Kulit dan Kelamin pada tanggal 23 Januari 2015 dengan diagnosis banding nevus pigmentosum, linear and whorled nevoid hypermelanosis.

Keluhan utama pasien tersebut adalah bercak berwarna hitam kecoklatan di lengan kanan atas sejak kurang lebih usia 12 tahun. Awalnya timbul beberapa bintik berwarna coklat muda (sewarna kulit) yang baru disadari sejak usia 12 tahun di lengan kanan atas yang semakin menggelap seiring bertambahnya usia dan menyebar hingga ke ketiak kanan. Pasien juga mengeluhkan beberapa bintik berwarna hitam kecoklatan yang teraba kasar di punggung yang baru disadari sejak 1 tahun yang lalu. Pasien tidak mengeluh gatal. Pasien menyangkal pernah mengalami infeksi kulit, minum obat dalam jangka waktu lama, luka atau trauma fisik di kulit akibat luka bakar atau prosedur kosmetik, gigitan serangga atau gatal karena kontak dengan suatu bahan di lengan kanan atas sebelum timbul bercak tersebut.

Riwayat penyakit keluarga, ayah, ibu dan adik perempuan pasien juga mengeluh bercak berwarna coklat muda hampir sewarna kulit yang sama seperti pasien sejak lahir. Berdasarkan pedigree tiga generasi, dapat dilihat bahwa penurunan penyakit sesuai dengan pola dominan autosomal.

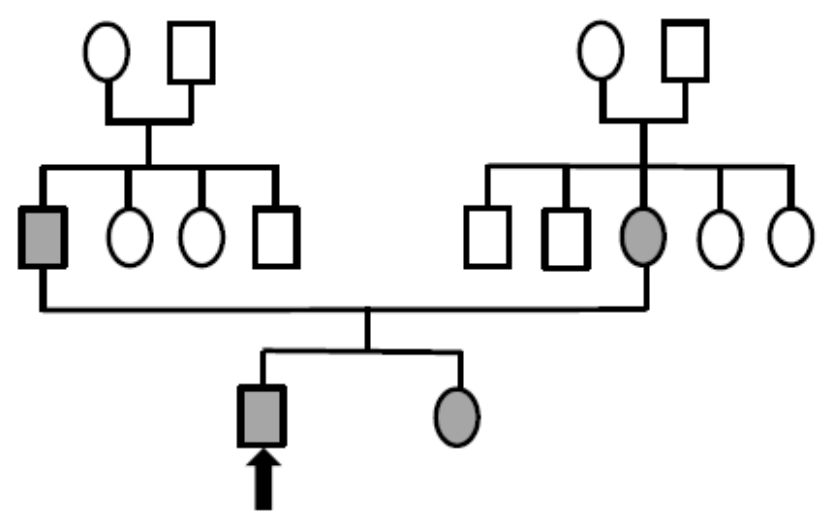

Keterangan:

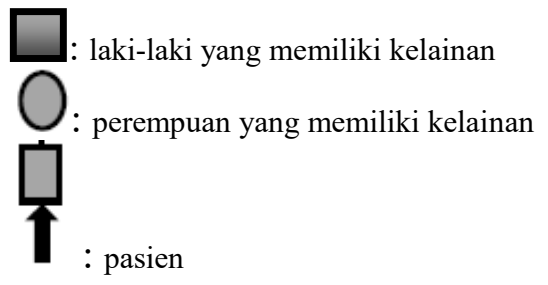

Gambar 1. Pedigree tiga generasi

Pada pemeriksaan fisik didapatkan berat badan 64 $\mathrm{kg}$, tinggi badan $175 \mathrm{~cm}$, keadaan umum baik, kesadaran kompos mentis, dengan tekanan darah 120/80 $\mathrm{mmHg}$, status generalis dalam batas normal.

Status dermatologis, pada bagian fleksural lengan kanan atas didapatkan makula hiperpigmentasi multipel, batas tegas, bentuk bulat, ukuran bervariasi dengan diameter $0,2-0,3 \mathrm{~cm}$, yang konfluen membentuk bercak geografis, ukuran $16 \mathrm{~cm}$ x $10 \mathrm{~cm}$ disekitarnya tampak papul multipel, bentuk bulat, diameter $0,2-0,3 \mathrm{~cm}$ hingga membentuk pola retikuler (Gambar 2). Pada punggung, didapatkan efloresensi papul hiperkeratotik folikuler comedo-like multipel, bentuk bulat, ukuran bervariasi diameter 0,1-0,2 cm (Gambar 3-5). Lokasi ketiak kanan dan kiri, didapatkan efloresensi makula hiperpigmentasi, soliter, batas tidak tegas, bentuk geografis, ukuran $2 \times 3 \mathrm{~cm}$ (Gambar 6-9). Tipe kulit menurut Fitzpatrick adalah tipe kulit IV. 


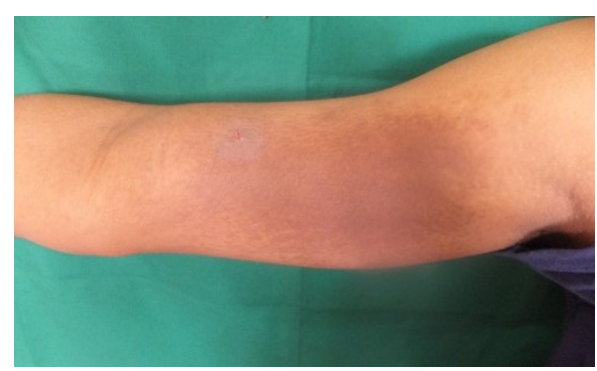

Gambar 2

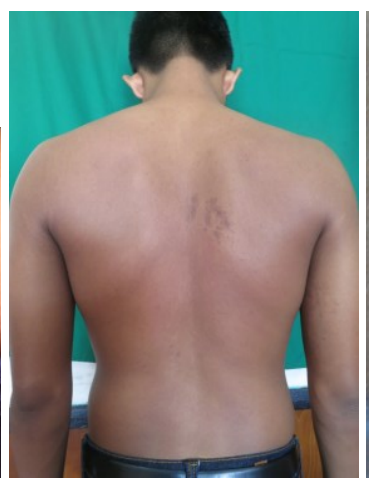

Gambar 3

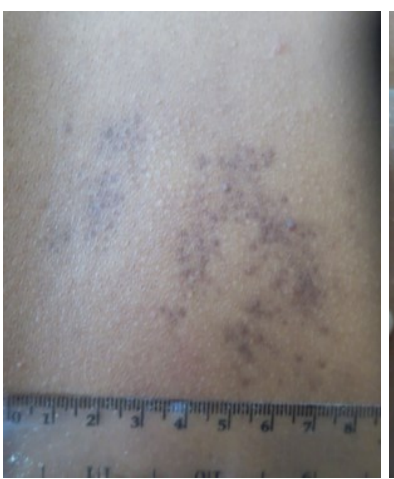

Gambar 4

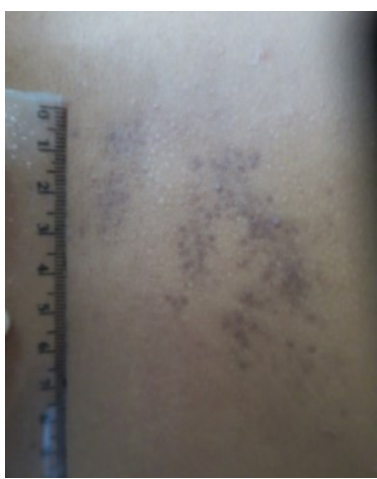

Gambar 5

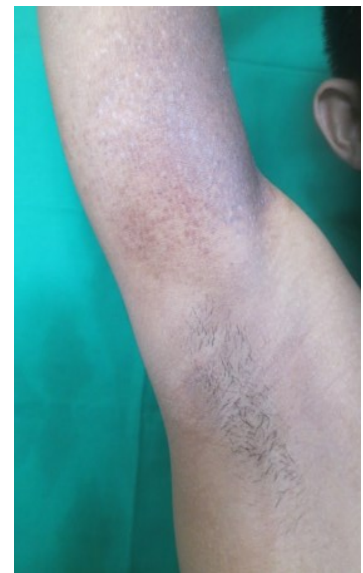

Gambar 6

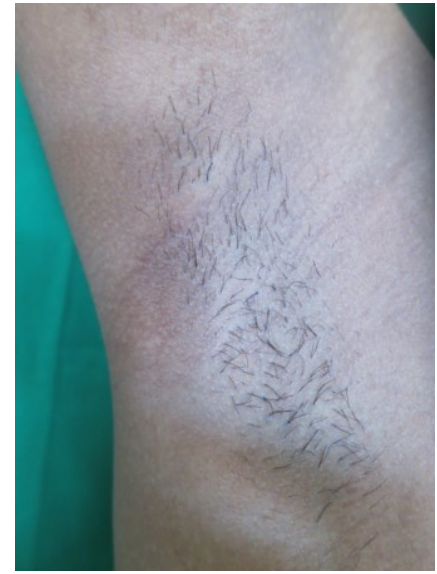

Gambar 7

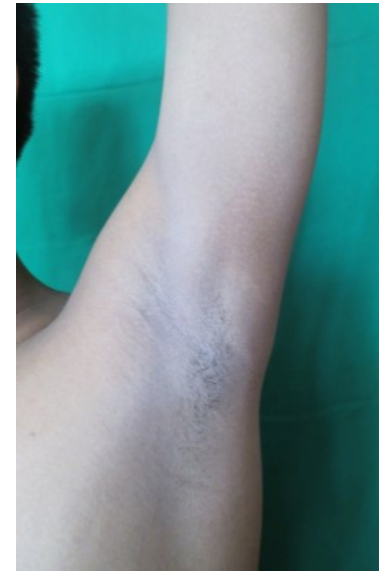

Gambar 8

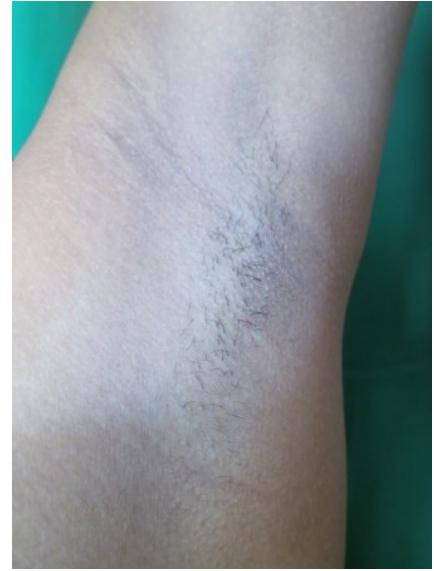

Gambar 9
Pasien didiagnosis dengan suspek linear and whorled nevoid hypermelanosis (LNWH) dengan diagnosis banding hiperpigmentasi pasca inflamasi (HPI) dan DDD. Dilakukan pemeriksaan penunjang berupa lampu Wood's, dermoskopi dan histopatologi. Hasil pemeriksaan lampu Wood's didapatkan peningkatan kontras warna kulit (Gambar 10). Pemeriksaan dermoskopi, didapatkan gambaran ireguler brownish projections di sekitar fokus hipopigmentasi (Gambar 11). Pemeriksaan histopatologis, pada lapisan epidermis tampak ketebalan normal sampai dengan akantosis ringan (dengan pola pemanjangan rete ridges/lentigo like pattern) disertai melanosis basalis yang prominen (diperkuat dengan pulasan histokimia Masson Fontana, pembesaran $10 \mathrm{x}$ 40), beberapa dengan aksentuasi pada ujung dari rete ridges (Gambar 12). Dermis atas mengandung pembuluh darah yang melebar dengan infiltrat ringan perivaskuler, terdiri dari beberapa limfosit, 1-2 eosinofil, dan sel mast (pewarnaan HE, pembesaran 10 x 40) (Gambar 13). Tampak pula melanin incontinence ringan pada dermis atas (pewarnaan Masson Fontana, pembesaran 10 x 40) (Gambar 14). Gambaran histologis, lokasi dan riwayat klinis lebih sesuai untuk familial asymmetrical DDD. 


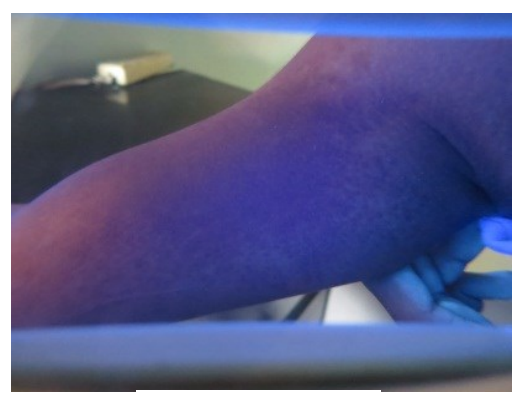

Gambar 10

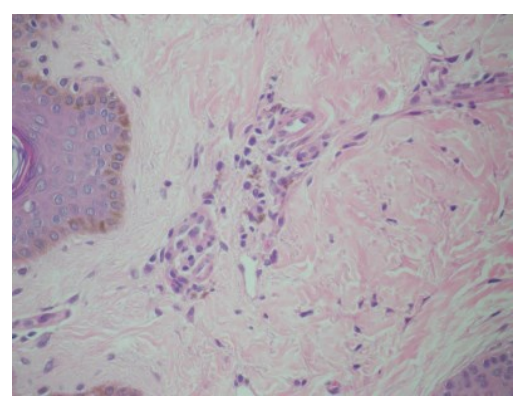

Gambar 13

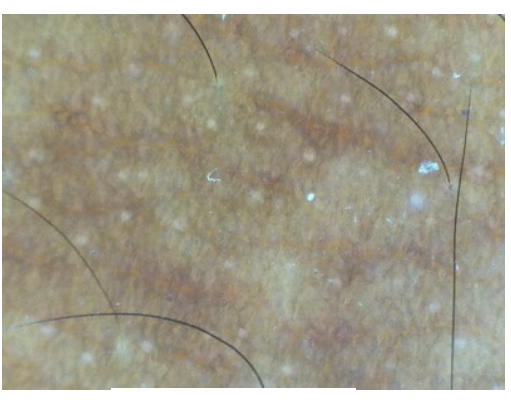

Gambar 11

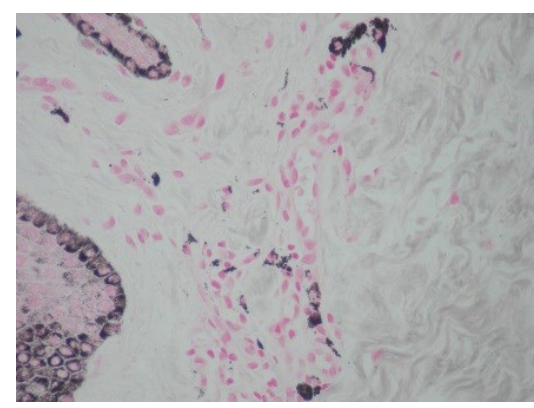

Gambar 14

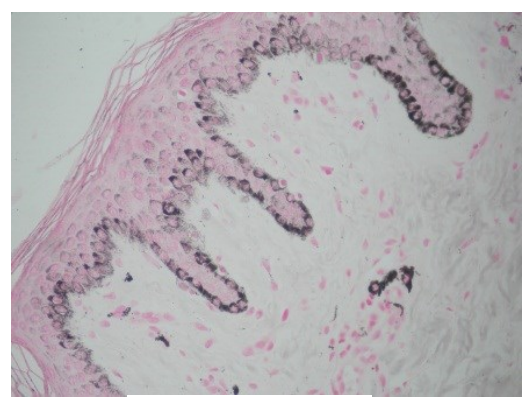

Gambar 12
Berdasarkan anamnesis, pemeriksaan fisik, dan pemeriksaan penunjang tersebut, ditegakkan diagnosis familial asymmetrical Dowling-Degos disease. Pasien diterapi dengan kombinasi laser $Q$-Switched Nd:YAG $1064 \mathrm{~nm}$, fluence $800 \mathrm{~mJ} / \mathrm{P}$, frekuensi $2 \mathrm{~Hz}$, menggunakan ukuran tip $4 \mathrm{~mm}$ dengan peeling kimiawi superfisial dan formula Kligman.

Hasil pengamatan setelah bulan kedua dilakukan terapi kombinasi laser dan peeling kimiawi superfisial sesi kedua didapatkan bercak kehitaman mengecil. Pada lengan kanan atas didapatkan efloresensi berupa plak hiperpigmentasi, batas tegas, bentuk geografika, ukuran mengecil menjadi $14 \mathrm{~cm} \times 7 \mathrm{~cm}$ (Gambar 15). Prognosis pada pasien adalah dubia karena meskipun ukurannya mengecil namun karena DDD adalah penyakit genetik maka lesi baru akan tetap muncul.

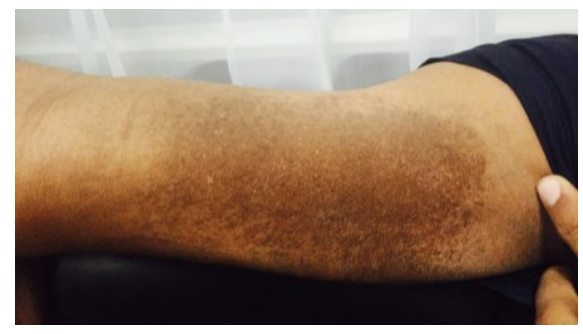

Gambar 15

\section{PEMBAHASAN}

Dowling-degos disease merupakan penyakit genodermatosis jinak dengan awitan lambat yang diturunkan secara autosomal dominan dan bersifat asimtomatis. ${ }^{1,8-10}$ Dowling-degos disease disebabkan oleh hilangnya fungsi mutasi pada domain head non helical dari gen 1 keratin 5 (KRT5) yang menyebabkan haplo-inssuficiency. ${ }^{3,8}$ Lesi DDD biasanya tampak saat pubertas atau dewasa muda, namun dapat juga tampak saat dewasa, yaitu usia 30 hingga 40 tahun. ${ }^{11}$ Lesi pigmentasi DDD berupa makula berwarna coklat kehitaman yang berkembang secara bertahap menjadi konfluen dengan pola retikuler atau "lacelike" dan pada daerah perifer tampak bintik berupa makula hitam kecoklatan, kadang ditemukan papul coklat kecil yang tersebar diskret. ${ }^{8,9,11}$ Pigmentasi dengan pola retikuler pada area fleksor biasanya terjadi simetris. ${ }^{1}$ Lesi tersebut awalnya mengenai daerah aksila dan inguinal, kemudian perlahan bertambah secara progresif ke daerah leher, lipatan inframammae atau sternal, badan, lengan bagian proksimal, fosa antekubiti, dan paha bagian dalam. ${ }^{1,8-10}$ Lesi tersebut jarang terjadi pada pergelangan tangan, wajah, skalp, skrotum dan vulva. ${ }^{6}$ Lesi pigmentasi tidak berubah dengan pajanan sinar matahari, namun kelainan tersebut biasanya tampak dan/atau memburuk setelah pubertas. ${ }^{2}$ Pada daerah wajah sering ditemukan pitted acneiform scars di daerah perioral. ${ }^{6}$ Pada daerah 
punggung dan leher dapat ditemukan lesi papul hiperkeratotik folikuler comedo-like., 3,89

Pada kasus ini, DDD terjadi pada seorang laki-laki berusia 18 tahun dengan keluhan bercak berwarna hitam kecoklatan di bagian fleksural lengan kanan atas dan punggung yang terletak pada area sisi kanan midline, dengan riwayat penyakit keluarga yang serupa. Hal tersebut berbeda dengan literatur yang menyebutkan bahwa DDD biasanya simetris. Tampilan klinis sesuai literatur karena awalnya bercak tersebut tampak berupa bintik berwarna coklat muda hampir sewarna kulit kemudian bertambah banyak, melebar dan makin menggelap dengan tampilan bintik coklat disekitar bercak yang konfluens dengan pola retikuler. Lesi makin melebar dan menggelap bukan karena pajanan sinar matahari tetapi kelainan ini memang memburuk setelah pubertas sesuai dengan literatur.

Diagnosis DDD ditegakkan berdasarkan gejala klinis dan didukung oleh pemeriksaan histopatologis dan dermoskopis yang khas. ${ }^{9,15}$ Gambaran histopatologis DDD didapatkan epidermis yang khas, yaitu akantosis ditandai dengan pemanjangan rete ridges yang sempit dan bercabang serta saling terangkai pada bagian dasarnya sehingga memberikan gambaran seperti tanduk. ${ }^{9,10}$ Tampak peningkatan pigmen melanin pada lapisan basal terutama pada daerah ujung dari papila dermis. ${ }^{1,6,8}$ Selain itu, dapat ditemukan dermal melanosis dan infiltrat limfohistiositik perivaskuler ringan. ${ }^{6,8}$ Dermoskopi pada lesi makula hiperpigmentasi DDD menunjukkan irreguler brownish projections di sekitar fokus hipopigmentasi. Irreguler brownish projections merupakan gambaran rete ridges yang memanjang dengan pigmentasi pada ujung papila dermis, sementara fokus hipopigmentasi menunjukkan adanya infundibulum folikuler. ${ }^{12}$ Untuk lesi berpigmen yang jinak harus dilakukan pemeriksaan lampu Wood's untuk membantu menentukan kedalaman letak pigmen di epidermis atau dermis. ${ }^{13}$

Pada kasus, pemeriksaan dermoskopis tampak irregular brownish projections disekitar fokus hipopigmentasi sesuai gambaran histologis yaitu adanya pemanjangan rete ridges disertai melanosis basalis dengan aksentuasi pada ujung rete ridges. Pada pemeriksaan lampu Wood's tampak peningkatan kontras warna kulit yang menunjukkan bahwa pigmen terletak di lapisan epidermis. Temuan ini sesuai dengan pemeriksaan histopatologis, yaitu adanya melanosis basalis yang prominen dengan aksentuasi pada ujung rete ridges. Secara keseluruhan gambaran histologis sesuai literatur namun karena lokasi dan riwayat klinis maka hasil pemeriksaan lebih sesuai untuk familial asymmetrical DDD.

Pasien awalnya didiagnosis suspek linear and whorled nevoid hypermelanosis (LNWH) dengan diagnosis banding HPI dan DDD. Linear and whorled nevoid hypermelanosis disebut juga "zosteriform lentiginous nevus", "zebra like hyperpigmentation in whorls and streaks", "reticulate hyperpigmentation distributed in a zosteriform fashion" dan "hyperpigmentation of Ijima" ditandai oleh makula hiperpigmentasi dengan konfigurasi seperti garis sepanjang garis Blascho tanpa riwayat inflamasi atau atropi sebelumnya. ${ }^{14}$ Pada pemeriksaan histopatologis tampak melanosis epidermis tanpa inkontinensia pigmen pada lapisan dermis. ${ }^{15}$ Pada kasus tetap dipertimbangkan suatu LNWH karena tidak ada riwayat inflamasi sebelumnya namun diagnosis LNWH dapat disingkirkan karena pada pemeriksaan histopatologis tidak ditemukan adanya inkontinensia pigmen pada lapisan dermis.

Pada hiperpigmentasi pasca inflamasi (HPI) tampak makula atau bercak hiperpigmentasi yang khas pada area kulit yang mengalami suatu proses inflamasi sebelumnya dengan gambaran histopatologis yaitu tampak inkontinesia pigmen dengan adanya akumulasi melanofag dan peningkatan melanin di lapisan atas dermis atau epidermis. Hiperpigmentasi pasca inflamasi lebih sering terjadi pada tipe kulit yang lebih gelap, yaitu kulit Fitzpatrick tipe IIIVI. ${ }^{14,16}$ Pada kasus, diagnosis banding HPI disingkirkan karena meskipun kulit pasien sesuai Fitzpatrick tipe IV namun pada pasien tidak ada riwayat inflamasi sebelumnya dan pada pemeriksaan histopatologis tampak akantosis ringan dengan pola pemanjangan rete ridges yang khas untuk lesi DDD.

Letak kedalaman pigmen pada lesi di kulit harus ditentukan untuk memilih modalitas terapi laser. Pada lesi berpigmen yang terletak di lapisan dermis dapat digunakan laser $Q$-Switched $\mathrm{Nd}$ :YAG dengan panjang gelombang 1064 nm, yang akan diabsorbsi dengan baik oleh melanin. ${ }^{17}$ Pada kasus, dilakukan dua kali laser $Q$ Switched Nd:YAG $1064 \mathrm{~nm}$ dengan fluence $800 \mathrm{~mJ} / \mathrm{P}, 2$ $\mathrm{Hz}$, ukuran tip $4 \mathrm{~mm}$ sesuai dengan letak pigmen pada lesi. Laser tersebut menggunakan pulse width fixed pada 20 nsec sesuai dengan TRT pada lesi berpigmen yang bervariasi antara 0,25 dan $1 \mu \mathrm{s}$. Tindakan laser dilakukan secara bergantian dengan peeling Jessner dikombinasi dengan TCA $10 \%$ untuk mengangkat pigmen melanin yang terletak pada lapisan epidermis. Prognosis pasien ini dubia karena meskipun ukuran lesi pada lengan kanan atas mengecil dari ukuran awal $16 \mathrm{~cm}$ x $10 \mathrm{~cm}$ menjadi 14 $\mathrm{cm} \times 7 \mathrm{~cm}$, namun lesi tersebut masih dapat terus berkembang secara bertahap karena penyakit ini merupakan penyakit yang diturunkan. Perlu dijelaskan kepada pasien bahwa terapi ini mungkin tidak akan memberikan hasil yang memuaskan karena lesi baru masih dapat terus muncul dan pengobatan ini membutuhkan waktu yang panjang.

\section{DAFTAR PUSTAKA}

1. Sardana K, Goel K, Chugh S. Reticulate Pigmentary Disorders. Indian J Dermatol, Venereol, and Leprol. 2013;79:17-29. 
2. Mukhi JI, Goyal M, Kamble AN, Singh RP. Dowling Degos Disease: Classic Clinicohistopatologic Presentation. VIJM. 2014; 17: 65-7.

3. Banihashemi $M$, Fazel Z, Meibodi NT, Imani M, Zabolinejad N. A Patient with Reticular Pigmentation. Iran J Dermatol. 2013;16: 42-4.

4. Georgescu EF, Stanescu. L, Popescu CM, Comanescu M, Georgescu I. Dowling-Degos Disease. Romanian J Morfol and Embryol. 2010; 51: 181-85.

5. Buku Register Rawat Inap Rumah Sakit Umum Pusat Sanglah Denpasar: 2010-2014.

6. Kavusi S, Lajevardi V, Moinedin F, Barzegar MR. What's Your Diagnosis: Dowling Degos Disease. Iranian $J$ Dermatol. 2008; 11: 93-4.

7. Mokos ZB, Lipozencic J, Ceovic R, Buzina SD, Kostovic K. Laser Therapy of Pigmented Lesions: Pro and Contra. Acta Dermatovenerol Croat. 2010; 18: 185-9.

8. Chang MW. Disorders of Hyperpigmentatiom. Dalam: Bolognia JL, Jorizzo JL, Schaffer JV, penyunting. Dermatology. Edisi ke-3. London: Elsevier Saunders; 2012.h.1049-74.

9. Zimmermann CC, Macedo PM, Alves MF, Sforza D, Abulafia LA, Carneiro SCS. Dowling-Degos Disease: Classic Clinical and Histopathological Presentation. An Bras Dermatol. 2011; 86: 979-82.
10. James WD, Berger TG, Elston DM. Disturbances of Pigmentation. Dalam: Andrews Disease of the Skin. Edisi ke-8. New York: Elsevier Saunders; 2011.h.846-62.

11. Nirmal B, Dongre AM, Khopkar UD. Dermatoscopic Features of Hyper and Hypopigmented Lesions of Dowling-Degos Disease. Indian J Dermatol. 2016; 61: 125-9.

12. Chan. NPY, Chan HHL. Epidermal and Dermal Color Improvement in Ethnic Skin: Pigment Lasers and Lights. Dalam: Alam M, Bhatia AC, Kundu RV, Yoo SS, Chan $\mathrm{HH}$, penyunting. Cosmetic Dermatology for Skin of Color. New York: McGraw-Hill; 2009.h.34-43.

13. Laperre H, Boone B, Schepper S, Verhaege E, Van Gelle M, Ongenae K, dll. Hypomelanois and Hypermelanosis. Dalam: Goldsmith LA, Katz SI, Glichrest BA, Paller AS, Leffel DJ, Wolff K, penyunting. Fitzpatrick's Dermatology in General Medicine. Edisi ke-3. New York: Mc Graw Hill; 2012.h.804-26.

14. Lernia VD. Linear and Whorled Hypermelanosis. Pediatric Dermatology. 2007; 24: 205-10.

15. Davis EC, Callender VD. Post Inflammatory Hyperpigmentation. J Clin Aest Dermatol. 2010;3:20-31.

16. Goldberg DJ. Pigmented Lesions, Tattoos and Disorders of Hypopigmentation. Dalam: Laser Dermatology. Victoria: Australia: Blackwell Publishing; 2008.h.73-113. 